\title{
Successful management of retinal metastasis from renal cancer with everolimus in a monophthalmic patient: a case report
}

\author{
Ismail Essadi 1,3*, Issam Lalya ${ }^{2,3}$, Mohamed Kriet ${ }^{3,4}$, Abdelhamid El Omrani3 ${ }^{3,5}$, Rhizlane Belbaraka 3,6
} and Mouna Khouchani $i^{3,5}$

\begin{abstract}
Background: The retina is an uncommon site for metastases, in particular from solid tumors. Some authors have reported a recent increase in the incidence of metastases in infrequent sites, such as brain or bone, probably due to the expanded treatment options and the resulting improved survival. Choroidal metastasis is the most common type of intraocular malignancy. The most common primary sites associated with choroidal metastasis are breast cancer in women and lung cancer in men. Treatment options are limited, but they must be discussed and adapted to the patient profile.
\end{abstract}

Cases presentation: We report a case of a 62-year-old Moroccan man with a history of monophthalmitis secondary to a war injury of 30 years' duration. He has been followed for 28 months for metastatic clear-cell renal carcinoma. The firstline treatment was effective for 24 months, before disease progression as retinal metastasis and accentuation of lung metastases. A second-line treatment with everolimus resulted in marked improvement of symptoms, complete recovery of visual function, and partial response in retinal localization.

Conclusions: Choroidal metastasis of renal cancer is a rare situation that must be actively sought in order to arrive at a suitable therapeutic approach.

Keywords: Retina, Metastasis, Clear cell carcinoma, Kidney

\section{Background}

The occurrence of retinal metastasis is a rare presenting manifestation of solid tumors [1]. Metastatic tumors are the most common intraocular malignancy in adults [1]. They are most commonly found in the choroid and less frequently in the iris and ciliary body [2]. Owing to its high vascularity, the posterior choroid is particularly exposed to blood-borne cancer cells [3]. Although symptomatic choroidal metastasis is less common than asymptomatic choroidal metastasis, visual disturbance caused by cancer

\footnotetext{
* Correspondence: ismail_onco@yahoo.fr

${ }^{1}$ Medical Oncology, Ibn Sina Military Hospital, Cadi Ayad University, Marrakesh, Morocco

${ }^{3}$ Cadi Ayad University, Marrakesh, Morocco

Full list of author information is available at the end of the article
}

metastasis from other organs is one of the most important limits on the quality of life of patients with cancer [4].

Therefore, further improvement of the therapy for visual disturbance is needed. Clinically available therapies for choroidal metastasis are currently very limited [5]. Chemotherapy causes systemic adverse effects and is not always effective. Radiotherapy provides local therapy but has several complications, including cataract, exposure keratopathy, iris neovascularization, radiation retinopathy, and radiation papillopathy $[5,6]$. We report a case of a patient successfully managed with everolimus as second-line treatment of retinal metastasis from renal cancer.

\section{Case presentation}

A 62-year-old Moroccan man presented to our hospital with a history of monophthalmitis secondary to a war 


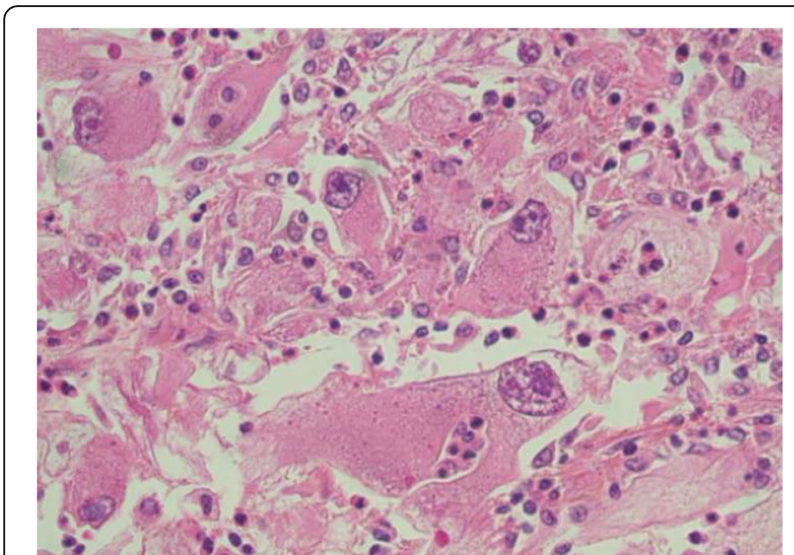

Fig. 1 Histological determination of clear cell carcinoma

injury sustained 30 years earlier. He had been followed for 28 months for metastatic clear cell renal carcinoma (Fig. 1). The secondary sites were represented by bilateral pulmonary nodules (Fig. 2). The first-line treatment with sunitinib $50 \mathrm{mg}$ per day (4 weeks on, 2 weeks off) was effective for 24 months and well tolerated. Clinical evaluation demonstrated a large visual field. An ophthalmological assessment with angiography showed the presence of a retinal tissue process (Fig. 3). A cerebral scan confirmed the presence of a retinal metastatic lesion without any cerebral localization (Fig. 4). The rest of the extension report was in favor of an increase in the number and size of pulmonary lesions.

A second-line treatment based on everolimus $10 \mathrm{mg}$ daily was started. Evaluation after 4 months revealed marked improvement of symptoms and complete recovery of visual function, despite the persistence of imaging-detected retinal metastasis that was significantly decreased in size (Fig. 5). The use of everolimus was associated with the occurrence of grade 2 mucositis, which rapidly resolved after symptomatic treatment.

\section{Discussion}

Retinal metastases are unusual complications of malignancies [1]. Nevertheless, some authors have reported a recent increase in the incidence of metastases in infrequent sites, such as brain or bone, probably due to the expanded treatment options and the resulting improved survival $[7,8]$.

The most common intraocular tumor is choroidal metastasis from lung cancer in men and breast cancer in women [8]. In the absence of specific series in the literature, the incidence of renal cancer metastasizing to the retina is certainly even lower than to other sites [9]. The prognosis of choroidal metastasis depends on its primary site [9].

The diagnosis is suspected on the basis of the appearance of visual disturbances and the presence of significant eye pain in a patient followed for cancer $[8,9]$. It is confirmed by retinal angiography, which shows nodular detachment $[8,9]$. Some imaging methods, such as magnetic resonance imaging (MRI) or computed tomography, can individualize a retinal process $[8,9]$. Fine-needle aspiration biopsy may be indicated in some situations, such as uveal metastasis without known primary tumor and patients requesting histopathological confirmation before undergoing recommended therapy such as enucleation [10]. Our patient could not benefit from an MRI, owing to the foreign body persisting within the left orbit since his war injury, which had caused the loss of his left eye 30 years ago. He was followed for evolutionary kidney cancer and did not require histological confirmation. Treatment options include observation if the patient is preterminal or the metastasis appears regressed; systemic therapy (immunotherapy, targeted therapy) or whole-eye radiotherapy if the metastases are multifocal, bilateral, or associated with extensive subretinal fluid; plaque radiotherapy for solitary metastasis; and enucleation, which is considered in very limited cases such as choroidal metastasis that is progressive and causes refractory pain [10-12].

Until recently, metastatic renal cell carcinoma was considered a cancer with a poor prognosis. Treatment options were limited to cytokines (interferon, interleukin 2). Recent years have been marked by the recognition of several small molecules in metastatic renal cancer [13]. Everolimus (RAD001) is an orally administered inhibitor of the mammalian target of rapamycin, a component of an

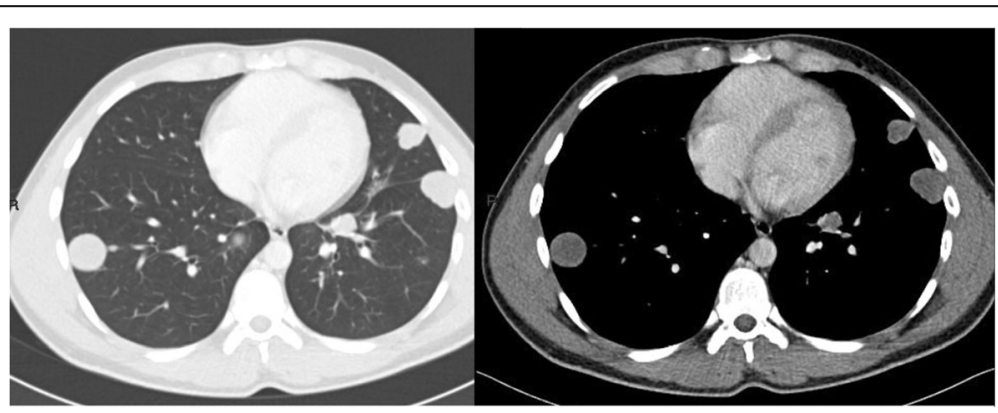

Fig. 2 Bilateral lung metastases 


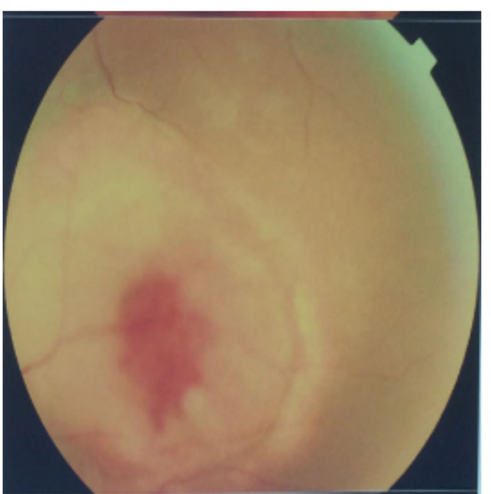

Fig. 3 Retinal angiography showing retinal tissue process

intracellular signaling pathway that regulates cellular metabolism, growth, proliferation, and angiogenesis [13, 14]. Everolimus has become individualized as a serious option after failure of antiangiogenic therapy [14]. Investigators in the RECORD-1 phase III trial compared everolimus with placebo in patients with metastatic renal cell carcinoma that had progressed while they were receiving sunitinib, sorafenib, or both [14]. Median progression-free survival (PFS) was significantly better in the everolimus arm (4.9 vs. 1.9 months; HR $0.33 ; P<0.001$ ), and $21 \%$ of patients had previously received one systemic treatment option. Median overall survival (OS) was similar between the two groups (HR 0.90; 95\% CI 0.71-1.14). The most common grade 3/4 adverse events in the everolimus arm were asthenia, stomatitis, pneumonitis, dyspnea, infections, fatigue,

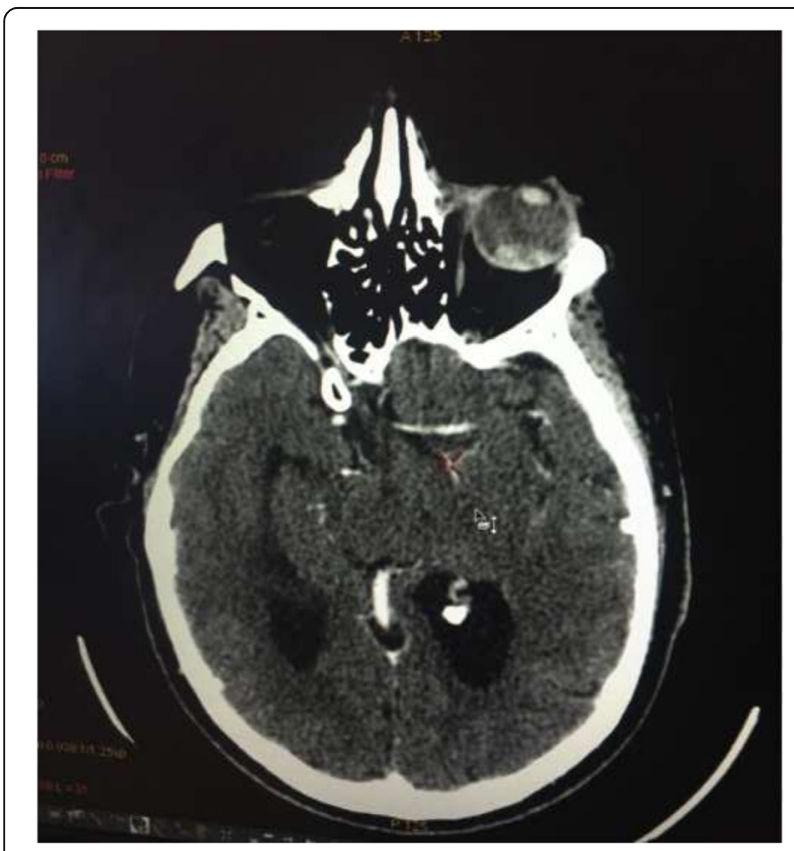

Fig. 4 Cross-sectional computed tomographic scan showing a retinal mass

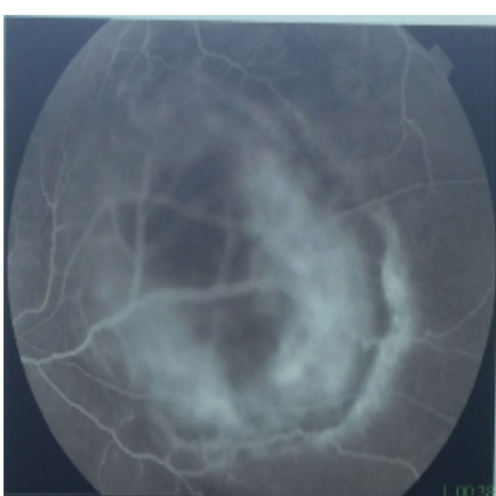

dehydration, and abdominal pain [14]. Updated analysis showed median OS of 14.8 months in the everolimus arm vs. 14.4 months in the control group (HR 0.87; $P=0.162$ ); however, preplanned crossover occurred in $79.9 \%$ of patients and probably confounded the survival benefit. Only $1 \%$ of patients in that study achieved a partial objective response [14]. Our patient had a clear partial response estimated to be $50 \%$ with a good tolerance of everolimus. Although the benefits of everolimus may need to be evaluated in clinical trials, this may not be feasible, owing to the rarity of the choroidal metastasis of clear cell renal cancer.

Nivolumab is a humanized antibody against programmed cell death protein 1 receptor. Researchers in a pivotal trial (CheckMate 025) enrolled 821 previously treated patients and randomized them to a nivolumab arm

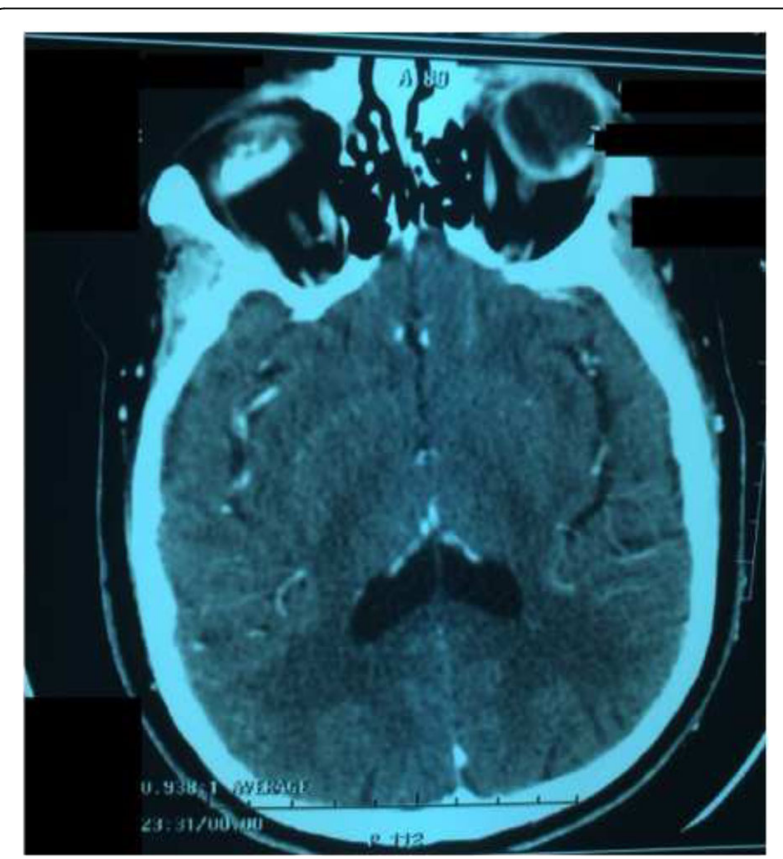

Fig. 5 Cross-sectional computed tomographic scan showing responsive retinal mass 
(3 mg/kg every 2 weeks) or an everolimus arm $(10 \mathrm{mg}$ daily). The primary endpoint of their study was OS. Nivolumab significantly improved median OS $(25.0$ vs. 19.6 months; HR $0.73 ; 95 \%$ CI $0.60-0.89 ; P=0.0018)$. The overall response rate was better with nivolumab (25\% vs. $5 \%$ ), whereas there were no difference in the median PFS (4.6 vs. 4.4 months) [15].

Cabozantinib is a multikinase inhibitor targeting vascular endothelial growth factor receptor, MET, RET, and AXL. These tyrosine kinases are involved in oncogenesis, metastasis, tumor angiogenesis, and drug resistance. METEOR was a phase III study in which researchers randomized 658 previously treated patients to cabozantinib $60 \mathrm{mg}$ daily or to everolimus $10 \mathrm{mg}$ daily. Median PFS (the primary endpoint of the study) was significantly better with cabozantinib (7.4 vs. 3.8 months; HR 0.58 ; $95 \%$ CI $0.45-0.74 ; P<$ $0.0001)$. The response rate was also better with cabozantinib (21\% vs. 5\%) [16]. Both nivolumab and cabozantinib are still not available in Morocco.

\section{Conclusions}

We present a case of a patient followed for metastatic clear cell renal cancer who had a large retinal mass on one eye that appeared while under treatment. This metastatic event is very rare. This case highlights the possibility of successful management of retinal metastasis by medical means. Thus, only a greater awareness of the problem will lead to choosing the best therapeutic approach to individual patients.

\section{Acknowledgements}

We sincerely thank Souad Tadlaoui for her assistance.

\section{Funding}

Not applicable.

\section{Availability of data and materials}

Not applicable to this report, because no datasets were generated or analyzed during the present study.

\section{Authors' contributions}

All authors read and approved the final manuscript.

Ethics approval and consent to participate

Not applicable.

\section{Consent for publication}

Written informed consent was obtained from the patient for publication of this case report and any accompanying images. A copy of the written consent is available for review by the Editor-in-Chief of this journal.

\section{Competing interests}

The authors declare that they have no competing interests.

\section{Publisher's Note}

Springer Nature remains neutral with regard to jurisdictional claims in published maps and institutional affiliations.

\section{Author details}

'Medical Oncology, Ibn Sina Military Hospital, Cadi Ayad University, Marrakesh, Morocco. ${ }^{2}$ Radiation Oncology, Mohamed V Military Hospital,
Rabat, Morocco. ${ }^{3}$ Cadi Ayad University, Marrakesh, Morocco. ${ }^{4}$ Ophthalmology, Ibn Sina Military Hospital, Cadi Ayad University, Marrakesh, Morocco.

${ }^{5}$ Radiation Oncology, Mohamed VI University Hospital, Cadi Ayad University, Marrakesh, Morocco. ${ }^{6}$ Medical Oncology, Mohamed VI University Hospital,

Cadi Ayad University, Marrakesh, Morocco.

Received: 6 May 2017 Accepted: 30 October 2017

Published online: 07 December 2017

\section{References}

1. Kreusel KM, Bechrakis N, Wiegel T, et al. Clinical characteristics of choroidal metastasis [in German]. Ophthalmologe. 2003;100:618-22.

2. Jardel P, Sauerwein W, Olivier T, et al. Management of choroidal metastases. Cancer Treat Rev. 2014;40:1119-28.

3. Leys AM, Van Eyck LM, Nuttin BJ, et al. Metastatic carcinoma to the retina: clinicopathologic findings in two cases. Arch Ophthalmol. 1990;108(10): $1448-52$.

4. Shields CL, McMahon JF, Atalay HT, Hasanreisoglu M, Shields JA. Retinal metastasis from systemic cancer in 8 cases. JAMA Ophthalmol. 2014;132(11): 1303-8. doi:10.1001/jamaophthalmol.2014.2406.

5. Shields CL, Shields JA. Choroidal and retinal metastasis. In: Arevalo JF, editor. Retinal and choroidal manifestations of selected systemic diseases. New York: Springer; 2013. p. 267-82.

6. Katsutoshi A, Akina K, Masanori M, et al. Factors affecting visual outcome in cases of lung cancer with choroidal metastasis initially presenting with ocular symptoms. Japanese Journal of Lung Cancer. 2011:51:94-8.

7. Kreusel KM, Bechrakis NE, Wiegel T, Krause L, Foerster MH. Incidence and clinical characteristics of symptomatic choroidal metastasis from lung cancer. Acta Ophthalmol. 2008;86(5):515-9.

8. Amer R, Pe'er J, Chowers I, Anteby I. Treatment options in the management of choroidal metastases. Ophthalmologica. 2004;218:372-7.

9. Demirci H, Shields $\mathrm{CL}$, Chao AN, Shields JE. Uveal metastasis from breast cancer in 264 patients. Am J Ophthalmol. 2003;136:264-71.

10. Ali MJ, Honavar SG, Vemuganti GK, Singh AD. Fine needle aspiration biopsy of retinal tumors. Monogr Clin Cytol. 2012;21:72-81.

11. Ye X, Kaliki S, Shields CL. Rapid regression of choroidal metastasis from lung cancer using erlotinib (Tarceva). Oman J Ophthalmol. 2014;7:75-7.

12. Lumi K, Yuriko B, Yusuke $Y$, et al. A case of choroidal metastasis from smallcell lung carcinoma diagnosed through ocular symptoms [in Japanese]. Atarashii Ganka. 2009;26:1687-91.

13. Choueiri TK, Motzer RJ. Systemic therapy for metastatic renal-cell carcinoma. N Engl J Med. 2017;376:354-66.

14. Motzer RJ, Escudier B, Oudard S, Hutson TE, Porta C, Bracarda S, Grünwald V, Thompson JA, Figlin RA, Hollaender N, Urbanowitz G, Berg WJ, Kay A, Lebwohl D, Ravaud A, RECORD-1 Study Group. Efficacy of everolimus in advanced renal cell carcinoma: a double-blind, randomised, placebocontrolled phase III trial. Lancet. 2008;372(9637):449-56.

15. Motzer RJ, Escudier B, McDermott DF, George S, Hammers HJ, Srinivas S, et al. Nivolumab versus everolimus in advanced renal-cell carcinoma. N Engl J Med. 2015:373(19):1803-13.

16. Choueiri TK, Escudier B, Powles T, Mainwaring PN, Rini Bl, Donskov F, et al. Cabozantinib versus everolimus in advanced renal-cell carcinoma. N Engl J Med. 2015;373(19):1814-23.

Submit your next manuscript to BioMed Central and we will help you at every step:

- We accept pre-submission inquiries

- Our selector tool helps you to find the most relevant journal

- We provide round the clock customer support

- Convenient online submission

- Thorough peer review

- Inclusion in PubMed and all major indexing services

- Maximum visibility for your research

Submit your manuscript at www.biomedcentral.com/submit
Biomed Central 